\title{
Effect of supplementary feeding on growth performance and ruminal fermentation in winter season grazing sheep
}

\author{
H.L. Hü ${ }^{1,2}$, D.X. Lu ${ }^{2,3}$ and Y.Z. Liu ${ }^{2}$ \\ ${ }^{1}$ Inner Mongolian Agriculture University \\ Inner Mongolian, 010018 Huhhot, P.R. China \\ ${ }^{2}$ Inner Mongolian Academy of Animal Sciences \\ Inner Mongolian 010030 Huhhot, P.R. China
}

\begin{abstract}
The experiment was conducted with twenty-four grazing sheep divided into 3 experimental groups on the basis of body weights, i.e control, optimal and non-optimal groups to study the effect of optimized supplementation on growth performance and rumen fermentation characteristics of grazing sheep in winter. The sheep in control were grazing only, whereas the grazing sheep in the optimal were supplemented with $250 \mathrm{~g}$ of an optimal forage mix and $404 \mathrm{~g}$ of concentrate (1) the animals in non-optimal were supplemented with $465 \mathrm{~g}$ of concentrate (2). Weight gain rate in the optimal increased by 1.2 and $15.3 \%$ as compared to that of the non-optimal and control group, respectively. Ruminal fermentation parameters were not significantly different between the optimal and non-optimal groups, however, they were significantly improved compared to the control. These results indicated that optimized supplementation strategies in winter were beneficial for markedly improving growth performance and rumen fermentation characteristics of grazing sheep .
\end{abstract}

KEY WORDS: sheep, grazing, supplementary feeding, growth performance, fermentation characteristics

\section{INTRODUCTION}

In northern China, there are vast areas of grasslands in both arid and alpine environments. These are used for grazing animals and support more than $55 \%$ of the sheep population in China. Due to seasonal changes, green pasture is usually available for only five months (approximately mid May to mid October) and dry pasture residues and low quality hays are the main sources of fodder for the

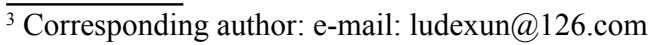


remaining seven months of each year. Therefore, the nutrient intake is not able to meet nutrient requirements of grazing animals solely from grazing in winter and spring. There is considerable opportunity for improving the supply of available nutrients, especially in winter and spring, through supplementation strategies that stimulates the intake of poorer quality feeds and /or increases the rate and level of rumen digestion (Lu, 1992).

The primary objective of this experiment was to study the effect of an optimized supplementation strategy on growth performance and rumen fermentation characteristics of grazing sheep in winter.

\section{MATERIAL AND METHODS}

Study site

The study was conducted in semi-desert grassland in Siziwang Banner of Inner Mongolia $\left(41^{\circ} 10^{\prime} \mathrm{N}\right.$ longitude, $110^{\circ} 20^{\prime} \mathrm{E}$ latitude, about $1430-1506 \mathrm{~m}$ in elevation), where the long-term averages of annual mean air temperature and annual rainfall are $2.9^{\circ} \mathrm{C}$ and $200 \mathrm{~mm}$, respectively. According to our spot field analysis the total number of plant species recorded was about twenty species. Stipa breviflora Griseb, Artemisia frigida Willd and Cleistogenes songorica Ohwi were the dominant plant species in this area.

\section{Experimental animals and management}

Twenty-four sheep were selected and randomly assigned to one of 3 treatment groups on the basis of weight: i.e the control, the optimal, and the non-optimal groups. All groups were grazed on natural grassland from 08.00 to $17.00 \mathrm{~h}$ followed by shed feeding at night. Fresh and clean drinking water was provided twice daily. Sheep in control group were grazed only in the whole period while sheep in optimal and non-optimal groups were fed by grazing plus supplementary feeding. From the start of experiment, sheep in the optimal group were supplemented with $250 \mathrm{~g}$ of an optimized forage mix (lucerne hay: millet straw: maize straw = 40:10:50) and $404 \mathrm{~g}$ the concentrate (1). after coming back from grazing at night. The optimized forage mix was designed and selected by the forage grading index (GI) technique proposed by Lu De-xun (Wang, 2005) in which the optimized forage mixture formula must have the maximum GI value with lowest cost. An equation for calculation of GI was as follows:

$$
\text { Grading index }(\mathrm{GI})=\frac{\mathrm{ME}(\mathrm{MJ} / \mathrm{kg}) \times \mathrm{CP}(\% \mathrm{DM}) \times \mathrm{DMI}(\mathrm{kg})}{\mathrm{NDF}(\% \mathrm{DM})}
$$


Then a further selection of the concentrates matched with the forage mixture by incubation in vitro technique as described by Wang (2005) was carried out. Sheep in non-optimal group were supplemented with $465 \mathrm{~g}$ of concentrate (2). The experimental diets were formulated to meet nutrient requirements of a 43 $\mathrm{kg}$ sheep by NRC (1985) (Table 1). Experimental periods lasted for 45 days. The experimental animals were weighed before feeding and watering in morning by the beginning and end of the supplementation period.

Table 1. Ingredient and chemical composition of supplementary concentrates for different groups, $\% \mathrm{DM}$ basis

\begin{tabular}{lcc}
\hline Items & \multicolumn{2}{c}{ Groups } \\
\cline { 2 - 3 } & $\begin{array}{c}\text { concentrate (1) for } \\
\text { optimized group }\end{array}$ & $\begin{array}{c}\text { concentrate (2) for } \\
\text { non-optimized group }\end{array}$ \\
\hline Ingredients, \%DM & & \\
$\quad$ maize & 86.2 & 83.2 \\
wheat bran & 4.9 & 2.1 \\
soyabean meal & 2.2 & 4.7 \\
urea & 0.2 & 1.9 \\
salt & 1.5 & 1.3 \\
calcium of fatty acids & 4.1 & 6.0 \\
Chemical composition, \% & & \\
CP & 9.81 & 14.39 \\
Ca & 0.32 & 0.49 \\
P & 0.23 & 0.27 \\
ME, MJ & 4.83 & 5.95 \\
\hline
\end{tabular}

\section{Collection of samples and chemical analyses}

Six sheep from each treatment groups were randomly selected. Rumen fluid samples were collected for six consecutive days by plastic tubes through mouth at 08.00 a.m. then ruminal $\mathrm{pH}$ was measured immediately with a portable $\mathrm{pH}$ meter (Horiba Cardy Compact pH meter model C-1; Spectrum Technologies, IL). Rumen fluid samples were strained through four layers of cheesecloth, and filtrate were mixed and pooled for each individual sheep and stored $\left(-20^{\circ} \mathrm{C}\right)$ for later analysis. VFA concentrations were detected by using crotonic acid as the internal standard with gas chromatograph (GC-2014, Sh Shzmadzu Janan) and flame-ionization detection, $\mathrm{NH}_{3}-\mathrm{N}$ concentration was determined by the colorimetry method (Gao and Feng, 1993).

\section{Statistical analyses}

The data obtained were analysed under one way analysis of variance (ANOVA) for comparing the means and significant differences between the experimental 
groups were assessed using Duncan's Multiple Range test using SPSS (version 11) statistical package.

\section{RESULTS AND DISCUSSION}

Table 2 presented the effect of different treatments on growth performance of grazing sheep, during the supplementation period. The body weight change of grazing sheep ranged from 43.40 to $46.4 \mathrm{~kg}$ in optimized group, 42.86 to $45.29 \mathrm{~kg}$ in non-optimized group, 44.75 to $41.00 \mathrm{~kg}$ in control group, respectively.

Table 2. Changes of weight gain of grazing sheep in different groups

\begin{tabular}{llll}
\hline Items & Optimal & Non-optimal & Control \\
\hline Initial weight, $\mathrm{kg}$ & $43.40 \pm 1.03^{\mathrm{a}}$ & $42.86 \pm 2.10^{\mathrm{a}}$ & $44.75 \pm 0.85^{\mathrm{a}}$ \\
Final weight, $\mathrm{kg}$ & $46.4 \pm 0.77^{\mathrm{a}}$ & $45.29 \pm 2.82^{\mathrm{a}}$ & $41.00 \pm 2.27^{\mathrm{b}}$ \\
Daily weight gain, $\mathrm{kg} / \mathrm{d}$ & 66.7 & 54.0 & -88.3 \\
\hline
\end{tabular}

a,b means of the same row with different superscripts were significantly different $(\mathrm{P}<0.05)$

There was a significant $(\mathrm{P}<0.05)$ difference in daily weight gain $(\mathrm{DWG})$ in three groups; DWG both optimized and non-optimized groups were $66.7 \mathrm{~g}$ and $54 \mathrm{~g}$, respectively. Whereas daily weight loss in control group was $88.3 \mathrm{~g}$. Body weight loss in case of control group was a clear reflection of their poor nutritional status as the nutrient intake was not able to meet their nutrient requirements solely from grazing. As shown in Table 2, weight gain rate increased by 15.3 and 14.1 percentile in the optimized and non-optimized groups as compared to that of the control group, respectively. and weight gain rate increased by $1.2 \%$ in the optimized group as compared to that of nonoptimized group. These results indicated that nutrients of pasture in winter were very low and not sufficient to meet the requirements of grazing sheep, which would prevent the achievement of high levels of sheep production, so appropriate supplementation strategies in winter could improve production performance, which was similar to earlier reports in ewes (Chaturvedi et al., 2001, 2003). As seen from Table 2, weight gain rate of animals in the optimized group was higher than those in the other groups. Present study also showed that the optimized supplementation strategies improved markedly growth performance of sheep grazing in winter.

Effect of different treatments on rumen fermentation characteristics in grazing sheep were shown in Table 3. There were no significant differences in rumen $\mathrm{pH}$ values between different groups. Rumen $\mathrm{pH}$ can be a useful tool for the optimization of ruminal digestion and nutrient supply to sheep. Ammonia-N $\left(\mathrm{NH}_{3}-\mathrm{N}\right)$ concentration and total volatile fatty acids (TVFA) concentration were not significantly difference between the optimized and non-optimized groups, however they were higher significantly than that of the control (Table 3). The 
Table 3. Effect of different treatments on rumen fermentation parameters of grazing sheep

\begin{tabular}{lccr}
\hline \multirow{2}{*}{ Items } & \multicolumn{3}{c}{ Groups } \\
\cline { 2 - 4 } & optimal & non-optimal & \multicolumn{1}{c}{ control } \\
\hline $\mathrm{pH}$ & $6.20 \pm 0.07^{\mathrm{a}}$ & $6.11 \pm 0.05^{\mathrm{a}}$ & $6.31 \pm 0.08^{\mathrm{a}}$ \\
Total VFA, mM/1 & $43.81 \pm 2.90^{\mathrm{a}}$ & $42.21 \pm 2.31^{\mathrm{a}}$ & $15.59 \pm 0.93^{\mathrm{b}}$ \\
$\mathrm{NH}_{3}-\mathrm{N}, \mathrm{mg} / 100 \mathrm{ml}$ & $15.11 \pm 0.90^{\mathrm{a}}$ & $16.31 \pm 1.56^{\mathrm{a}}$ & $10.13 \pm 0.96^{\mathrm{b}}$ \\
\hline
\end{tabular}

${ }^{a, b}$ means of the same row with different superscripts were significantly different $(\mathrm{P}<0.05)$

associative effects of feedstuffs may occur when forages with different types, species and qualities are mixed together. The results from the present experiment showed that supplementation of concentrates plus forage mixture or concentrate only to grazing sheep enhanced $\mathrm{NH}_{3}-\mathrm{N}$ and TVFA production, which indicated associated effects between different forages or between forage and concentrate might existed in the optimized and non-optimized groups, especially, the positive associative effects occurred might bigger in the optimized than that of the non- optimized. These results showed that supplementation strategies were beneficial for improving fermentation characteristics of grazing sheep, and the optimized supplementation was an more beneficial strategy.

\section{CONCLUSIONS}

The results of the present study confirmed optimization supplementation strategies in winter could improve markedly growth performance and rumen fermentation characteristics of grazing sheep.

\section{REFERENCES}

Chaturvedi O.H., Bhatta R., Santra A., 2003. Effect of supplementary feeding of concentrate on nutrient utilization and production performance of ewes grazing on community rangeland during late gestation and early lactation. Asian-Austr. J. Anim. Sci. 16, 983-987

Chaturvedi O.H., Mishra A.S., Antra A., Karim S.A., Jakhmola R.C., 2001 Effect of supplementary feeding during late gestation on production performance of ewes grazing on community rangeland. Indian J. Anim. Sci. 71, 714-717

Gao M., Feng Z.G., 1993. A improved method of chromium derermination. Inner Mongolian J. Anim. Sci. Prod. 3, 42-43

Lu D.X., 1992. A new supplementation strategy for ruminants-integrative manipulation of nutritional systems (in Chinese). Contemp. Anim. Husb. 1, 2

Wang X., Lu D., 2005. Associated effects among several feedstuffs in vitro. In: Proceedings of the $5^{\text {th }}$ Joint Symposium of Japan-Korea-China on Rumen Metabolism and Physiology. ISSN, pp. 99 